\title{
Technologically mediated learning: The future of training in Australia
}

\author{
Peter J. Hosie \\ Ngee Ann Polytechnic \\ Singapore
}

\begin{abstract}
Following a review of the economic imperatives currently facing Australia, the future directions training will take are examined. Related training issues are considered; such as multiskilling, on-the-job training and legal issues. The author predicts that technologically mediated learning (TML), especially interactive multimedia, will gain ascendancy as the predominant mode of delivery for training.
\end{abstract}

\section{Current business climate}

Before making some predictions about the direction training may take in Australia, it seems logical to take stock of the present business environment. Ultimately, decisions about where training will head will be tied to the fortunes of the world economy. Smith (1988: 72) provides a sobering description of life in corporate Australia:

In the 1970s Australia was poised to become the world's commodity toyshop with mountains of minerals and cheap energy to buy. In the 80s we have awoken from this prosperous dreamtime to a harsh economic environment in which our primary exports have lost ground in face of decreased demand and foreign competition. Our sheltered manufacturing sector has been exposed to import competition The deregulation of financial markets provided plentiful cash to fuel an unprecedented spate of acquisitions and speculative investment which sent share markets to dangerously dizzy heights. Our balance of payments went seriously into deficit, unemployment became the lot of many young people and managers and workers alike were shaken out of shrinking organisations. Then to cap it all down came the markets bringing with them the paper castles of entrepreneurs and small investors alike. 
Anyone neglectful enough to ignore Smith's account of the last twenty turbulent years in Australia's economic affairs will be well advised to heed the aphorism: those who fail to understand the past are bound to repeat it. More effort will have to be expended on developing the country's human capital potential if the scenario described by Smith (1988) is not to be repeated. Watkins (1989) extends this view and postulates that organised capitalism is in the process of being replaced by more fluid economic circumstances. Indeed there are indications of profound change occurring to Western industrialised economies (Lash \& Urry, 1987); these changes must affect the way organisations in Australia view human capital. As organisations grapple with an increasingly dynamic competitive environment, so people resources will be increasingly seen as an important competitive advantage.

Link this reality with Australia's present training effort and part of the reason for the malaise of the economy will be apparent (DEET, 1988: 8):

- a large proportion, perhaps as many as one-third of Australian enterprises, spend nothing on formal training;

- the firms which do undertake formal training spent, on average, something between 2 and 2.5 per cent of gross wages and salaries on structured formal training in 1988; and

- the level of commitment to training varies significantly among enterprises; some adopt best practices approaches while others do nothing.

\section{A difficult upbringing}

Training in Australia has experienced a rather neglectful upbringing. Indeed there is ample evidence (Dawkins, 1988) demonstrating the failure of Australian industry to contribute to an effective training climate. These quotes from disparate sources - one a union leader and the other reporting the attitude of management - indicate the position of training in Australia: 'We are as a nation I think are just waking up to the importance of training, it is not deeply ingrained in our culture so it tends to be undervalued by management and the workers themselves and not always done properly ...' (Gary Weaven, ACTU Assistant Secretary, 1989), and 'Staff training, along with career path development and employee motivation and satisfaction, were listed as the top three areas in which personnel departments have failed to meet the needs of senior management' (Bosman, 1984: 6). Only recently has the union movement come to realise that training has something to offer employees and that it is linked to industry reskilling incentives. The crucial question is not whether the union and management will reconcile their differences but how they will. More effective training methodologies need to be developed to enable this to occur. 
According to Downs (1989) jobs of the future will require less memorising of facts and procedures, fewer physical skills, and far more conceptual ability. The American Society for Training and Development Futures HRD Task Force (ASTD, 1984) and Models for HRD Practice (McLagan, 1990) present impressive lists of training and development trends. Some of the more significant aspects of these predictions will be discussed here - such as how developments in computer-assisted learning, interactive videodisc technology and telecommunications delivery methods will change the way training is conceived, designed and delivered. There is remarkable congruence between American Society for Training and Development's now five-year-old projection and emerging training trends in Australia.

\section{On-the-job training}

In reporting the Training Commission's (UK) survey of employees' training activities Sloman (1989) gives the most comprehensive (2000 sample interviews) and recent (1986 / 7 financial year) review of employers' training ever undertaken. From this considerable array of data some trends are discernible. Almost half of employees' training, measured by either volume or cost, was conducted at the normal workplace. On-the-job training in the UK is now a major method of progressing new recruits, developing apprentices and long term trainees, and for teaching employees new skills. This is especially the case when updating and upgrading skills involving the implementation of new equipment and methods. While this trend is not as well-established in Australia, the Training Guarantee Act should result in increases in on-the job training. A considerable degree of on-the-job training already occurs in Australia which is yet to be documented and is poorly recognised as a legitimate organisational activity. Few companies are adequately planning or resourced for its implementation. If statistics for on-the job training from the UK (Sloman, 1989) are indicative of the circumstances in Australia, then it is likely that training delivered on-site will become a more legitimised activity in the future.

\section{Multiskilling}

Government motivation to move training back into the workplace is largely based on arguments about international competitiveness, relevance and shifting the burden of vocational training onto industry. In Australia Reconstructed (ACTU/IDC, 1987) the argument is put squarely that if Australian industry is going to be competitive overseas, then greater investment in raising the level of skills and technology needs to be coupled with preventing skills obsolescence. In response to the ACTU initiative, the Business Council of Australia (1988) supported the principle of flexible work design and went on to suggest that skill formation was 'at a premium'. That this represents a rare consolidated view from two 
traditional adversaries is apparent - both consider that more skilled workers are required to contribute to national productivity. While government and unions may consider that human capital is very important, it is still far from being more important than other forms of capital, as judged by the business sector. The Australian Conciliation and Arbitration Commission endorsed the principle of 'structural efficiency' as a basis for reorganising federal industrial awards which has been linked to a new national wage system. Some of the more important structural efficiency principles include:

- the lateral mobility of workers across occupations (multi-skilling and broadbanding);

- vertical skilling (establishment of skill-related career paths for workers).

Both these initiatives encourage employees to expand their skill base through participation in structured training activities. A composite picture emerges. Trainers will need to articulate clearly their requirements and liaise far more actively with external training agencies who in turn will be encouraged to deliver training programs in situ. Eventually it should be possible to accredit in-house courses with external agencies such as TAFE; such accreditation would be a further incentive for workers to participate. Thus learning may come to be considered a legitimate employmentrelated activity rather than something that is seen as a discrete exercise delivered by external agencies. Unions are likely to pursue these training activities actively in order to win wage rises and ensure career progression. The role of trainers will involve transforming the workplace into an environment where learning has real value.

This change will have to be undertaken in close partnership with line managers who must be convinced to 'buy into' (Peters, 1989) the initiatives to ensure success of the venture. Highly-skilled trainers will need to be allocated to various line-managers for extended periods to work directly with the client to whom the service will be delivered on an as-needed project basis. In essence, training managers will have to disabuse themselves of the notion that centralised training will be the continuing modus operandi. Other methods of training which are not closely linked to corporate objectives, such as the 'cafeteria approach' (Kane, 1986), will rapidly become a luxury enjoyed in times past. Training managers will, of course, be responsible for coordinating the activities of trainers to see they are meeting the corporate goals, as well as putting out the line managers' training 'bushfires'. Evaluating the effectiveness of training against corporate goals is an activity on which training managers will need to focus more. 


\section{Legal implications for trainers}

Recent legislation and legal precedent will have a long-term effect on trainers, especially with regard to training functions. Like any externally imposed requirement, co-operation is usually only forthcoming when compliance is obligatory.

\section{Training}

Probably the most dramatic illustration of the import of recent applicable legal decisions is the case of an LPG tanker operator employed by Boral Gas (Qld) Pty Ltd who was dismissed for overfilling customers' LP gas tanks. The decision by the Queensland Industrial Court centred on the ineffectiveness of Boral's safety training efforts. Significantly it was held that simply supplying employees with training is inadequate preparation; instead 'Organisations will have to prove that the training was effective' (Delahaye and Smith, 1987: 6). Flowing from this case is a clear warning to employers to provide effective training. Smith and Delahaye (1988: 118) consider this means employees will need to demonstrate that:

- full training needs analysis is carried out;

- a significant part of the training needs analysis includes job analysis to ensure that the full and correct procedures are included in training courses;

- training courses are professionally designed to ensure that maximum learning occurs;

- training courses are conducted by training officers who can be proven to be competent;

- training courses are evaluated, especially in the areas of individual learning and appropriate behaviour back on the job;

- full training records are kept.

The corollary of the Boral case is that organisations could now face negligence claims resulting from alleged ineffective training. Given that the public and the workforce have become increasingly litigious, it is merely a matter of time before such a case reaches the courts. Clearly, post-Boral, organisations now have an extended duty of care to train their workforce effectively to protect both the employee and client from potential injury or economic loss (Davies, 1989). If the tanker driver employed by Boral had unwittingly injured a member of the public, and simultaneously caused economic loss by overfilling a client's gas cylinder, liability to Boral could have been substantial.

Given the lack of attention in Australia to international trends in training and development, it seems appropriate that industry awoke to the need 
for competent training and development for their employees following an incident involving a deficient training scheme. In essence the industrial legal system has used the precedent of this case to give advanced warning of the consequences of inadequate training and development. When this requirement is combined with employee training obligations under the Training Guarantee Act, the direction training initiatives should take is becoming apparent. This will need to be reflected in the quality of training provided to management as well as non-supervisory staff.

\section{Technologically mediated learning (TML)}

Technologically Mediated Learning (TML) is one important way this can be achieved. TML satisfies the criteria for delivering training which is of high quality and "defensible" in terms of ensuring effective learning strategies are employed.

Of great concern is the tendency of training professionals to concentrate on technologically high end applications of telecommunications technology before other potentially more cost-effective solutions are thoroughly investigated. Despite what the advertising agencies and pundits would have us believe, no one form of technology, no matter how appealing, will be a panacea for all training needs. If organisations are going to benefit from TML then there is urgent need for both trainers and managers to become conversant with its potential applications.

\section{Interactive multimedia}

\section{Computer based training}

Indications are that trends to the use of Computer Based Training (CBT) will continue but not at the same rate some believe desirable. Trends reported by Smith (1988) in the USA indicate that courses produced internally by companies are replacing off-the-shelf and university style courses, and this is tentatively confirmed in Australia (Curtain, 1987). Smith and Delahaye (1988: 133) suggest the trend to CBT 'will be accelerated considerably by the advent of user-friendly authoring systems ... [which] overcome one of the major stumbling blocks to the widespread use of CBL [CBT]'. Unfortunately the availability of easy-to-use CBT authoring packages does not in itself necessarily simplify the design or implementation of CBT. Hosie and Jamieson (1988) explain how even relatively simple tasks like selecting a CBT productivity tool, such as an authoring language, can prove to be a daunting task when there are over 100 packages to choose from. Also trade-offs related to economies of scale and the adoption of individualised learning techniques need to be resolved. 
For non-supervisory staff CBT has many advantages over traditional training techniques, such as supporting standardised testing and certification, which will increase in importance as award restructuring becomes an ongoing process. Well-designed CBT supports the principles of andragogy (adult learning) and will become increasingly important as a way of implementing self-directed learning. Also CBT has a capacity to make learning interactive for large numbers of people on a cost-effective basis. While CBT does offer individually-paced learning and some selection based on learner responses, these are essentially predetermined by the design of the courseware. But it is essential that designs do not overly restrict learner responses causing CBT packages to become the antithesis of self-directed learning.

The design and creation of quality CBT is more dependent on effective Instructional Design than authoring systems. Simply giving trainers a productivity tool like a CBT authoring language is certainly no guarantee that effective learning will occur. The design process is qualitatively different for CBT. Successfully designing of CBT involves far more than just manipulating text and graphics on a computer screen. Indeed even competent CBT designers take at least 100 hours to produce one hour of quality CBT. Dabbling by inadequately trained designers will result in many of the economic learning powers of CBT being dissipated. There are few competent, professionally trained CBT designers in Australia and the quality of software produced is variable. Unless the standards of CBT produced are kept high it will fall into disrepute and will fail to deliver the productivity gains predicted.

\section{Interactive videodisc}

Of all the TML available, interactive videodisc (IVD) has the potential to have the most immediate impact on training. There are a number of misconceptions about IVD, so an explanation of the technology is warranted as is a close examination of the efficacy of the technology to deliver training.

IVD can be considered a subset of the emerging multimedia technologies. It is worth observing, as Fletcher (1990: 1V-1) did (albeit now some three years ago), "At present there is no hardware technology that can competitively provide the functionalities that interactive videodisc systems can, but digital video, digital audio, and compact disc technology are all developing rapidly and will soon claim at least some of the territory now held by interactive videodisc systems." Of these disc-based technologies CD-ROM, or one of its many digital derivatives, is emerging as the next format to be widely adopted by training providers.

Interactive video represents the fusion of video and computer technology.

(Parsloe, 1983, p.83). Teh and Perry (1984, p.2) suggest that IVD 'represents

the synthesis of the instructional capabilities of television and the 
computer', while De Bloois (1982, p.33) suggests '... it is an entirely new medium with characteristics quite unlike each of the composites'. The key points of this fusion, as Bosco (1984) points out, is that the information on a videodisc can be controlled by the microprocessor so that the system reacts to learner behaviours. Moving images, stills, computer graphics and printed information can be combined and structured into an instructional unit which can readily interact with the learner.

A number of applications of IVD for training have been isolated. IVD is particularly effective for teaching mechanical and procedural skills. (Priestman, 1984). The cost of developing IVD with even a reasonable amount of interactivity is great in terms of man hours and technology. Media production, especially broadcast quality television, requires a large investment in equipment, and high labour costs. Competent planning is vital with this medium if costs are to be contained and a long shelf life of the courseware is to be assured. (Hosie, 1987a: 5)

Muller and Leonetti (1992, p. 17) have summarised the advantages of using IVD for instruction:

- Timeliness

- Flexible Training Periods

- Effectiveness

- Multiple Applications

- Validated and Documented Effectiveness

\section{Time and cost considerations}

Of all the dimensions by which IVD can be judged, the capacity to reduce the time spent on training is the most clearly quantifiable advantage for the technology. When used appropriately, IVD can reduce training time compared with traditional training methods. Time savings using IVD are reported to be in the order of a minimum of $30 \%$, and a maximum of $60 \%$ (Geber and Pribble, 1989). As in all business, time means money; so savings in training time can be equated to increased profitability or efficiency for organisations.

De Bloois' (1988) review of 30 studies of military, government, military and educational uses of IVD between 1980-87 makes the case for the cost effective use of IVD in training. Also commenting in the defence training context, Fletcher (1990) observed that investments in IVD are paid back during the lifetime of the courseware. Unlike conventional training methods, the bulk of cost of IVD are incurred during the development phase, not prior to delivery. But subsequent delivery and maintenance costs are low. The Institute for Defense Analysis (1990) has established that IVD lessons are significantly less costly (average savings of 64\%) than traditional methods. Break-even analyses can readily establish the point when IVD becomes a cheaper method (compared to conventional approaches) of delivering instruction (Brandt, 1987). In contrast to 
instructor or paper dominated training methods, the cost per user for IVD applications decreases every time the courseware is used.

\section{Implications for teaching and learning}

Fletcher's (1990, p. V-1) quantitative, analytical review of 47 studies related to using IVD in defence training and education concludes that IVD is effective in "... many different instructional settings and many different instructional objectives, interactive videodisc instruction is both more effective and less costly than conventional instruction." In all instructional settings and applications IVD resulted in around an 0.5 standard deviations improvement over conventional approaches to instruction. Other important conclusions reached by Fletcher's study include: IVD being; increasingly effective when more interactive features are used, equally effective for knowledge and performance outcomes and being less-costly than conventional classroom instruction. Overall Fletcher (1990) concluded that IVD was sufficiently cost-effective and user demand great enough for it to be routinely utilised in defense training.

The data available suggests that IVD is an effective teaching and learning medium, especially in the area of training simulation. Removing the variability of human teaching is a major advantage of IVD courseware. Kearsly (1983) observes, computers have certain advantages in instructional settings, such as permitting "students to learn at their own pace, individual learning styles are considered, resulting in increased student satisfaction. Most importantly, there is more control over learning materials and learning processes" (p.14).

From an extensive review of the literature Brandt (1986) identified a number of situations where the use of IVD should be considered for a training delivery system. These were:

- to gather together a large collection of multimedia material such as slides or a mixture of slides and motion sequences on film or video;

- a large number of learners are distributed over time and place;

- teachers with subject matter expertise are in short supply;

- equipment simulation is required;

- the situation requires continuous practice and/or retraining;

- the subject matter is relatively stable;

- the training involves the teaching of processes, procedures, problem solving, and decision making;

- learners vary in experience and/or entry level skills;

- there has to be a better way.

Combining the visual stimulation of moving and still images with the interactive capabilities of computer technology has resulted in a potentially powerful learning medium. Learner acceptability of the 
medium is established. Reasons for this positive disposition relate to convenience, capacity for review, motivation and general feeling that people are in control of their learning environment. The level of skills acquired by learners is the most crucial measure of the success of IVD. When compared with traditional techniques IVD is able to equal, and in some cases exceed, established practices and is often preferred to traditional teaching methods because it can be completed when it is convenient for students, not trainers.

New courseware designs, which do not rigidly structure learner responses, need to be explored to complement this medium of instruction. Successful adoption of IVD depends on developing quality courseware which takes into account the unique attributes of the technology. Experience to date indicates that IVD designs are only just beginning to exploit the capacity of the technology.

There is an increasing array of useful IVD software available for industry. However, take-up rates are relatively low and development costs high, so only well-targeted applications with demonstrable cost-benefit pay-offs are likely to occur in the short term. When industry becomes attuned to using TML methods there is likely to be an increased use of IVD as a training delivery and certification device. Cost justification becomes all the more important when TML approaches are adopted.

\section{Telecommunications technologies}

Training managers should not underestimate the difficulty of convincing management to accept the validity of overseas research and practice (Hosie, 1987b; Lange, 1984), indicating the instructional effectiveness of using telecommunications or other forms of TML to deliver and administer education and training on a large scale. As Hosie, Charman and Atkinson (1991: 117) observe, 'management often lacks the essential knowledge base to make informed decisions' in this area. This lack of technological understanding also extends to a fair number of training managers and trainers. What training professionals do possess is often rather simplistic. As Hosie, Charman \& Atkinson, 1991:117,118) consider that:

Australian educational technologists face the challenge of convincing management to invest in telecommunications for some important aspects of education and training. Despite well proven overseas models and ample evidence to indicate the cost and learning effectiveness (Hosie, 1987,1988; Lundin, 1988) of using telecommunications, Australia has been slow to take advantage of possibilities the technology offers. Why is this so?

As Lange (1984) accurately ventures: fear, apathy, lack of encouragement and ignorance are the main reasons why implementation of telecommunications technology for the delivery and administration of 
education and training has lagged behind in Australia. Not surprisingly these disincentives have resulted in a lack of effective policy developments. Without well-researched and marketed policy there is unlikely to be forward motion.

Educational and training administrators and policy developers in Australia could be fairly accused of all of Lange's sins in relation to developing the uses of telecommunications technology but they cannot all be overcome instantly. Also, decision-makers in education have been elevated to their management positions before these technologies became widely used.

One obvious deficiency is the lack of information and understanding of telecommunications technologies throughout the general community, including amongst lecturers, teachers and trainers. What understanding people have is fragmented, disjointed and often confused with commercial brand names. High-end applications such as video conferencing are the most known and sought after by educators and trainers. However, once awareness is raised and sources of information provided, considerable interest may be shown in alternative technologies of a simpler and more affordable nature. Often, facilities are available for use but knowledge of their application to education and training is limited. (Hosie, Charman \& Atkinson, 1991).

Hosie, Charman and Atkinson (1991) provide a comprehensive description and analysis of telecommunications suitable for use in education and training:

1. Broadcasting

1.1 Radio

1.2 Talkback radio

1.3 Television

1.4 Talkback television

2. Fixed/mobile radio communication

$2.1 \mathrm{HF}$ radio

2.2 Satellite mobile (Mobilesat)

3. Teleconferencing

3.1 Audio teleconferencing

3.2 Audiographic teleconferencing

3.3 Computer conferencing

3.4 Video teleconferencing

4. Peripherals

4.1 Electronic whiteboard

4.2 Facsimile

4.3 Slow scan video

4.4 Interactive video disk

5. Computer-mediated communications

5.1 Electronic mail

5.2 Videotex

5.3 Voicemail

6. Ancillary communications services

6.1 FM subcarrier

6.2 Teletext 
Summaries similar to the one illustrated were provided by the Office of Communications for each of these services and technologies, together with appropriate definitions of technical terms. An indication was given also on the suitability of each service for delivering education to individuals, in small, medium and large learning groups. (Hosie, Charman \& Atkinson, 1991).

The WA Government's then Office of Communications (1989) have provided a compact reference point to assist trainers and managers to make decisions related to using telecommunications technologies. Each service, technology or application has been rated on a five-point scale. The rating scale uses " 1 " as the least desirable or most difficult and " 5 " as the highest or most desirable. This permits information about various telecommunications technologies potentially useful to trainers to be scanned so an appreciation and summary of each feature can be quickly gained.

While the terms "low" and "high" may not represent relative measures, they do indicate extremes on a continuum. As a general guide each point was rated with both the provider (agency or teacher) and user (student) in mind. In an effort to keep the rating simple, many factors which influence the selection were combined into general headings, resulting in some loss of detail but giving improved readability. Ratings assumed typical use in an educational or training environment. (Hosie, Charman \& Atkinson, 1991).

\begin{tabular}{lllllr}
\hline Affordability factor & \multicolumn{2}{c}{ low } & \multicolumn{3}{c}{ high } \\
$\quad$ Initial outlay & 1 & 2 & 3 & 4 & 5 \\
Recurrent & 1 & 2 & 3 & 4 & 5 \\
Hardware & 1 & 2 & 3 & 4 & 5 \\
Software & 1 & 2 & 3 & 4 & 5 \\
Maintenance & 1 & 2 & 3 & 4 & 5 \\
Additional support staff & 1 & 2 & 3 & 4 & 5 \\
\hline Ease of use factor & low & & & \multicolumn{2}{c}{ high } \\
Hardware ease of use & 1 & 2 & 3 & 4 & 5 \\
Software ease of use & 1 & 2 & 3 & 4 & 5 \\
Materials preparation & 1 & 2 & 3 & 4 & 5 \\
\hline Access factor & low & & & & high \\
Perth metropolitan area & 1 & 2 & 3 & 4 & 5 \\
Country towns & 1 & 2 & 3 & 4 & 5 \\
Country areas & 1 & 2 & 3 & 4 & 5 \\
Remote areas & 1 & 2 & 3 & 4 & 5 \\
To equipment & 1 & 2 & 3 & 4 & 5 \\
\hline
\end{tabular}




\begin{tabular}{lllllr}
\hline Teacher and learner factors & \multicolumn{3}{c}{ low } & \multicolumn{3}{c}{ high } \\
Interactivity with students & 1 & 2 & 3 & 4 & 5 \\
Retention of ordinary teaching methods & 1 & 2 & 3 & 4 & 5 \\
Control pace and sequence of lesson & 1 & 2 & 3 & 4 & 5 \\
Review previous instructions & 1 & 2 & 3 & 4 & 5 \\
Generate text & 1 & 2 & 3 & 4 & 5 \\
Generate graphics & 1 & 2 & 3 & 4 & 5 \\
Hear students & 1 & 2 & 3 & 4 & 5 \\
See students & 1 & 2 & 3 & 4 & 5 \\
Hear teacher & 1 & 2 & 3 & 4 & 5 \\
See teacher & 1 & 2 & 3 & 4 & 5 \\
\hline
\end{tabular}

Many aspects of training, delivered using traditional methods, are suited to TML systems. I predict that professionally skilled trainers who are capable of designing, delivering and evaluating training using new technology will eventually overtake trainers using traditional methods. Already there is a strong unmet demand for Instructional Designers in this area.

Despite the fears of trainers, the introduction of TML does not spell the demise of all conventional learning techniques, such as classroom-based instruction. In fact many TML delivery techniques, especially those involving real-time telecommunications, can be conceived of as an extension of traditional training techniques which can assist trainers to become more effective but before TML can become 'institutionalised', management needs to be convinced of its efficacy.

\section{Open learning}

What is often missing from considerations about using TML for training is a rational philosophical grounding of the approach proposed. Even those eager to 'get the show on the road' need to pause to consider why a certain approach is proposed, for example CBT, when other methods may suffice. But more importantly, trainers need to articulate to senior management the rationale behind their approaches. For example, as Kearsley suggests, designs are needed which permit 'students to learn at their own pace, [where] individual learning styles are considered, resulting in increased student satisfaction. More importantly, there is more control over learning materials and the learning process' (Kearsley, 1983:14). Another trend is strongly towards Open Learning which is now such a pervasive international trend that it seems sure to endure primarily because it has the interest of the learner (not the trainers or institutions) at the core of its 
philosophy. Open Learning supports the concept of a systems approach to self-directed learning techniques which actively involve individuals in developing their own learning styles. To develop Open Learning packages, training managers will need professionally qualified and experienced Instructional Designers preferably with a knowledge of TML.

\section{Conclusion}

As profit margins become tighter, and foreign competition even more aggressive, so organisations will go for the bottom line; learning will simply become another competitive tool. Spitzer (1988b: 32) alerts us to the fact that in the USA, great sums of money were being invested into training, but there was little performance improvement to show for it, because there was relatively little correlation between training and performance'. Spitzer (1988b) has isolated the conditions under which effective performance can be optimised: these require meaningful commitment from management for performance improvement. Also, in identifying the success factors involved, Spitzer (1988b) has provided a number of quantifiable parameters that trainers should attend to. For example, trainers need to become more au fait with the corporate dynamics of profits and productivity, and plan their programs to assist organisations attain these. Using strategic planning to achieve these aims will become an increasingly important activity, a view also endorsed by Latham's (1988: 549) meta-analysis of training trends, which concluded, 'training needs must be linked to corporate strategy'.

In an effort to avoid repeating an unfortunate image problem, training professionals need to 'move away from having to rely on goodwill towards creating a more 'business like' image by greater focus on solving organisational performance problems, on cost-benefit ratios, and upon quantifiable results' (Kane, 1986: 43). Trainers need to be less concerned with enhancing learning as an end in itself and become more focused on improving performance. Fitz-enz (1989) considers that in the future trainers' activities must focus on results not activities, concentrate on customer goals and always create value. In contrast Latham (1988: 561) considers that economic measures are primitive and that: 'seeing a positive behaviour change on the part of subordinates will result in upper management treating training seriously - more seriously than if presented with dollar estimates that justify time spent on training'. Despite surface disagreements these views are not irreconcilable - the economic cost and value of changing behaviour through training can, and will be considered by organisations much more closely.

There can be little doubt that the primary role for managers in the 21st century will be the continuing development of their people' (AITD, 1988: 8). Smith and Delahaye (1988: 136) indicate some directions this might take: 
- the need to adjust to, adopt, and prepare others for complex technology;

- the need to meet the changing expectations of trainees and organisations;

- the need to move towards the status of 'professional' for trainers;

- the need to conduct, and then use, extensive research on training in Australia.

- the need to meet the growing legal requirements attaching to organisations.

There is strong evidence to suggest that effective learning by employees will become far more important than at any time before. This is driven by factors such as: government policy, international market forces and the growing awareness by employees that a highly-skilled workforce is at least as important as its capital assets for an organisations' long-term survival and prosperity. Organisations that wish to survive will need to engage in strategic planning to identify future skills shortages and devote adequate resources to training employees to fill those gaps. TML will become a way organisations develop these skills and maintain their competitive edge.

\section{References}

ACTU/TDC (1987). Australia Reconstructed. Canberra: AGPS.

AITD (1988). Industry Training in Australia: The Need for Change.

Brisbane, Australian Institute of Training and Development.

ASTD HRD Futures Task Force (1984). HRD Tomorrow. Training and Development Journal, November, 58-65, 84.

Bosman, B. (1984). The Office or the Boardroom? The Role of the Personnel Manager in the Future. Unpublished MBA Project, Faculty of Business Sydney: New South Wales Institute of Technology.

Brandt, K. (1986). Interactive video: When to Consider its Use. San Jose State University. ERIC ED272174.

Business Council of Australia (1988). Editorial. Business Council Bulletin, Nov Dec, 4-11.

Business Council of Australia, Interim Council on Productivity and Training (1988). Productivity and Training: Proposals for the Establishment of a State Employment and Skills Development Authority, April, Perth.

Bosco, J. \& Wagner, J. (1988). A Comparison of the Effectiveness of Interactive Laserdisc and Classroom Video Tape for Safety Instruction of General Motors Workers. Educational Technology, 28(6), 15-22.

Curtain, R. (1987). Skill Formation and the Enterprise. Labour and Industry, 1(11), 8-37.

Davies, M. (1989). Damages For Purely Economic Loss and Causation, Paper No. 2. Perth, WA: Law School, University of Western Australia. 
Dawkins, J. (1988). Industry Training in Australia: The Need for Change. Canberra: Department of Employment, Education and Training, AGPS.

DEET (1988). Industry Training in Australia: The Need for Change. Summary. Canberra: AGPS.

Delahaye, B. and Smith, B. (1987). Warning - Now You Have to Prove You Trained Them. Human Resource Management Australia, 2(6),17-22, 25.

Downs, S. (1989). Retraining for New Skills. Ergonomics, 28,1205-11.

Fitz-enz, J. (1988). Proving the Value of Training. Personnel, March, 17-22.

Fitz-enz, J. (1989). Human Value Management. Fitz-enz Forecast, 1-4.

Fletcher, J. (1990). Effectiveness and Cost of Interactive Videodisc Instruction in Defence Training and Education, Institute for Defence Analysis, Arlington, Va, July.

Hedberg, J. \& Perry, N. (1984). Design of Interactive Video Materials: Problems and Prospects. Paper presented to the Computer-Aided Learning in Tertiary Education Conference, Brisbane, September.

Hedberg, J. \& Perry, N. (1985). Human Computer Interaction and CAI: A Review and Research Prospectus. Australian Journal of Educational Technology, 1(1), 12-20. http: / / www.ascilite.org.au / ajet / ajet1 / hedberg1.html

Hedberg, J. \& Perry, N. (1985). Learning Task Requirements and the Design of Interactive Video. Paper presented to the Annual Conference of the Association for Educational Communications and Technology. Anaheim, California, Jan 1985.

Hosie, P. (1986). Some Theoretical and Methodological Issues to Consider When Using Interviews for Naturalistic Research. Australian Journal of Education, 30(2), 200-11.

Hosie, P. (1987a). Adopting Interactive Videodisc Technology for Education. Educational Technology, 27(7), 5-10.

Hosie, P. (1987b). Satellites and Education - Learning from International Experience. British Journal of Educational Technology, 18(1), 60-76.

Hosie, P., Charman, T., and Atkinson, R. (1991). Informing managers about telecommunications technologies for education and training. Australian Journal of Educational Technology, 7(2), 117-126. http:/ / www.ascilite.org.au/ajet/ajet7/hosie.html

Hosie, P. and Jamieson, D. (1988). Plenty of chaff - some wheat: Evaluating CBT authoring packages for industry and education. In J. Steele and J. G. Hedberg (eds), Designing for Learning in Industry and Education, 208223. Proceedings of EdTech'88. Canberra: AJET Publications. http: / / www.ascilite.org.au/aset-archives/confs/edtech88/ hosie.html

Kane, R. (1986). A Strategic Look at Training and Development. Human Resource Management Australia, 24(3), 42-52.

Kearsley, G. (1983). Computer-Based Training: A Guide to Selection and Implementation. Reading, MA: Addison Wesley.

Lange, J. (1984). 12 Issues in Australian Tertiary Telecommunications. Paper presented to RMIT Conference, Satellite Communications in Australian Tertiary Education, 1-21. 
Latham, P. (1988). Human Resource Training and Development. Annual Review of Psychology, 39, 545-583.

Lash, S. and Urry, J. (1987). The End of Organised Capitalism. Cambridge: Polity Press.

Maglen, L (1988). Challenging the Human Capital Orthodoxy: The Education and Productivity Link Re-examined. Paper presented at AARE, Armidale, University of New England

Leonetti, R. (1992). Instructional Delivery Systems, July / August.

Lyness, A. (1987). Performance and Norms of Time for Adult Learners Instructed in CPR by an Interactive Videodisc System. Paper presented at the 5th Annual Conference on Research in Nursing Education, San Francisco, January 14-16.)

Manning, D. et al. (1983). Student Acceptance of Videodisc Based Programs for Paramedical Training. Technological Horizons in Education, 11(3), 105-108.

McLagan, P. (1990). Models for HRD Practice. American Society for Training and Development.

Myers, D. (1986). Classroom, Self-Paced and On-The-Job. Data Training, January, 22-4.

Office of Communications (1989). Appropriate Telecommunications Services, Technologies and Applications for Education and Training. Perth: Department of Computing and Information Technology (now State Services).

SESDA (1988). Productivity Training: Proposals for the Establishment of a State Employment and Skills Development Authority. Perth Interim Council on Productivity and Training, April, iii, 2.

Sloman, M. (1989). On-The-Job Training. Personnel Management, February, 38.

Smith, B. (1988). Training and Development: Shaping the Competitive Human Resource Edge. Human Resource Management Australia, 26(1), 72-80.

Smith, B. and Delahaye, B. (1988). Training and Development in Australia: A Review. In G. Palmer (ed.), Australian Personnel Management: A Reader. Macmillan: Melbourne.

Spitzer, D. (1988a). Strategic Thinking: The Key to Training Success. Educational Technology, February, 34-35.

Spitzer, D. (1988b). Performance is the Bottom Line. Educational Technology, March, 32-34.

Swain, A. and Francis, P. (1988). Human Resource Development in Australia. A Survey Looking at the Current State of the Art in Australia's Top Profit Makers. Curtin University of Technology, October, 1-4.

Swain, P., Warren-Langsford, P. \& Francis, A. (1990). Australia HRD at Crossroads: A Discussion of the Current Debate on Labour Market Reform. Asia Pacific HRM, 28(4), 13.

Training Interviews Tom Peters (1989). Training, June, 47-55. 
Watkins, P. (1989). Organised Capitalism ... Education and the Flexible Workplace. Unicorn, 15 (3 August) 139-44.

Zemke, R. (1987). Training in the 90s. Training, January, 4-53.

Author: Peter J. Hosie BEd, BA (Hons), MBus is currently a Senior Educational Development Officer with Ngee Ann Polytechnic's Educational Development Centre and is responsible for the design and development of multimedia learning materials. Prior to this, Peter was Head of Media Production at Ngee Ann, a Human Resource and Training Consultant in Australia, a Personnel Project Officer at the University of WA, an Executive Officer for the WA Government's Task Force on Telecommunications in Education and Training, a Training Program Designer for SECWA, an Education Officer with the Audio-Visual Education Branch of the Education Department of WA and a secondary school English teacher. He has published over 25 major papers on technologically mediated learning and human resource development/management as well as being involved in the design and production of many educational TV programs, some involving interactive techniques.

Please cite as: Hosie, P. J. (1993). Technologically mediated learning: The future of training in Australia. Australian Journal of Educational Technology, 9(1), 69-86. http:/ / www.ascilite.org.au/ajet/ajet9/hosie.html 